\title{
The Impact of Aerobic Training on Cardiovascular Reactivity to and Recovery from Challenge
}

\author{
Richard P Sloan, PhD ${ }^{1,6}$, Peter A Shapiro, MD², Ronald E DeMeersman, PhD $^{3}$, Emilia \\ Bagiella, $\mathrm{PhD}^{4}$, Elizabeth N Brondolo, $\mathrm{PhD}^{5}$, Paula S McKinley, $\mathrm{PhD}^{1,6}$, Olga Crowley, \\ $\mathbf{P h D}^{1}$, Yihong Zhao, $\mathbf{P h D}^{1}$, Joseph E. Schwartz, $\mathbf{P h D}^{7}$, and Michael M Myers, $\mathbf{P h D}^{6}$ \\ ${ }^{1}$ Division of Behavioral Medicine, Department of Psychiatry, Columbia University, New York NY \\ 10032 \\ ${ }^{2}$ Division of Consultation/Liaison Psychiatry, Department of Psychiatry, Columbia University, New \\ York NY 10032 \\ ${ }^{3}$ Department of Rehabilitation Medicine, Columbia University, New York NY 10032 \\ ${ }^{4}$ Division of Biostatistics, Mailman School of Public Health, Columbia University, New York NY \\ 10032 \\ ${ }^{5}$ Department of Psychology, St. John's University, Jamaica NY 11439 \\ ${ }^{6}$ New York State Psychiatric Institute, New York NY 10032 \\ ${ }^{7}$ Department of Medicine, Columbia University Medical Center, New York NY 10032
}

\section{Abstract}

Objective-To test the hypothesis that aerobic but not strength training would lead to attenuated reactivity to and more rapid recovery from cognitive and orthostatic challenge and that deconditioning would reverse this effect.

Methods-We conducted a randomized controlled trial (RCT) contrasting the effects of aerobic vs. strength training on HR, 4 indices of RR interval variability (RRV), and blood pressure (BP) reactivity to and recovery from psychological and orthostatic challenge in 149 healthy, young, sedentary adults. Subjects were randomized to 12 -week aerobic or strength training programs and studied before and after training and again after 4 weeks of sedentary deconditioning. The data were analyzed by performing a Group (aerobic vs. strength) by Session (study entry, post-training, and deconditioning), by Period (baseline, speech, Stroop, math, tilt) 3-way ANOVA with prespecified contrasts of the effect of group assignment on reactivity and recovery.

Results-Aerobic capacity increased in response to conditioning and decreased after deconditioning in the aerobic but not the strength-training group. However, the two groups did not differ on HR, RRV, or BP reactivity to or recovery from laboratory challenge.

Conclusions-These findings, from the largest RCT to address this matter to date, raise doubts about attenuation of reactivity or enhancement of recovery as a putative mechanism underlying the cardioprotective effects of aerobic exercise.

\section{Keywords}

Exercise; heart rate; autonomic nervous system; reactivity; randomized controlled trial

Corresponding Author: Richard P. Sloan, Ph.D., Division of Behavioral Medicine, Department of Psychiatry, Columbia University, 1150 St. Nicholas Ave., Suite 121, New York, NY 10032, TEL 212-851-5575, FAX 212-851-5580, rps7@ columbia.edu. 
Aerobic training for more than 3 hours per week elicits functional adaptations resulting in improved cardiorespiratory efficiency. Many studies have reported cardioprotection and a significant delay in all-cause mortality associated with higher levels of physical fitness (1-3) and an increase in mortality among those who decrease exercise activity (4). There is a doseresponse relationship between fitness and survival but the magnitude of this benefit tends to decline as fitness levels increase. These improvements have been shown to take place in people of all ages (5-7). The evidence for the health benefits of physical activity is so great that consensus panels have consistently recommended exercise as a central activity of a healthy life (8-10).

A number of biologic mechanisms have been proposed to explain how physical activity might decrease the risk of coronary artery disease (CAD) in normal subjects and slow its progression in patients with existing heart disease. Platelet adhesiveness and aggregability are depressed by exercise training (11). Through several different mechanisms, training lowers metabolic demands of the myocardium or increases its electrical stability (12). Abnormalities such as chronic activation of the adrenergic system with concomitant decreases in vagal activity have been shown to be independent predictors of increased cardiovascular mortality (13-16). In patients with moderate to severe congestive heart failure, exercise training leads to significant improvements in functioning, with a significant shift from sympathetic to parasympathetic dominance of cardiovascular autonomic control after training (17).

Some evidence suggests that elevated cardiovascular reactivity to, and reduced recovery from, challenging events may be related to the risk of CAD (18-22) and reactivity and recovery appear to be related to physical activity and fitness. Like psychological stressors, acute exercise elicits increases in HR, secondary to withdrawal of cardiac parasympathetic and increased sympathetic activity, as well as increases in BP. After chronic exercise training, however, these increases are reduced at equivalent workloads (23). Reduced HR reactivity to and more rapid recovery from an acute bout of exercise are associated with reduced risk of developing cardiovascular disease in healthy populations (24) and of exacerbation of existing disease in CAD patients (25).

Exercise-induced improvements in reactivity to and recovery from psychological and orthostatic challenge would be consistent with this evidence. Moreover, such a finding is consistent with the cross-stressor adaptation theory (26) that holds that adaptations to exercise stress lead to adaptations of the responses to other challenges.

An early meta-analysis of 34 studies of fitness and reactivity to psychological challenge found evidence for attenuated psychophysiological responses to stress in fitter individuals (27). A more recent meta-analysis also concluded that fitness was associated with improved reactivity and recovery (28) but another found no support for this hypothesis (29). Most studies addressing this matter are either cross-sectional or naturalistic follow-up studies rather than randomized controlled trials.

To address this matter, we conducted a randomized controlled trial contrasting the effects of aerobic vs. strength training on HR and RR interval variability (RRV) reactivity to and recovery from psychological and orthostatic challenge in healthy, young adults. Subjects were studied before and after training and again after 4 weeks of sedentary deconditioning. 


\section{METHODS}

\section{Study Design}

The study was a randomized controlled trial of aerobic vs. strength training on RRV, at rest and in response to challenge. All subjects provided informed consent. The Institutional Review Boards of Columbia University Medical Center and St. John's University approved this study.

\section{Study Participants}

We sought healthy, sedentary young adults, $18-45$ years of age. Subjects were recruited by flyers posted around the two universities.

Subjects were eligible if they did not exercise regularly or exceed American Heart Association standards for average fitness $\left(\mathrm{VO}_{2} \max \leq 43\right.$ and $37 \mathrm{ml} / \mathrm{kg} / \mathrm{min}$ for men and women respectively). Exclusion criteria included current symptoms of affective disorder, psychosis, or substance abuse, current usage of psychotropic medication, and any medical condition that affected the autonomic nervous system or cardiovascular system.

We received 1195 phone calls in response to the recruitment flyers. Four hundred twelve participants provided written informed consent, of whom 263 were disqualified because they had scheduling difficulties, exceeded $\mathrm{VO}_{2}$ max criteria, or had resting systolic blood pressure $>140 \mathrm{mmHg}$ or frequent premature ventricular contractions (> 6/min) during $\mathrm{VO}_{2} \mathrm{max}$ testing. The remaining 149 participants were randomized to either the aerobic $(\mathrm{N}=74)$ or strength training ( $\mathrm{N}=75)$ group. Data collection began in December 1998 and ended in January 2003.

Each subject received a 6-month membership in a fitness facility and $\$ 300$ for participation in the study.

\section{Determination of Aerobic Fitness}

After phone screening to determine eligibility, maximum aerobic fitness $\left(\mathrm{VO}_{2} \max \right)$ was assessed by a graded exercise test on an Ergoline 800S electronic-braked cycle ergometer (SensorMedics Corp., Anaheim, CA). Each subject began exercising at 30 watts (W) for two minutes, and the work rate was continually increased by $30 \mathrm{~W}$ every two minutes until $\mathrm{VO}_{2}$ max criteria ( $\mathrm{RQ} \geq 1$.1, increases in ventilation without concomitant increases in $\mathrm{VO}_{2}$, achievement of maximum age-predicted heart rate, and/or volitional fatigue) were reached. Minute ventilation was measured by a pneumotachometer connected to a FLO-1 volume transducer module (PHYSIO-DYNE Instrument Corp., Quogue, NY). Percentage of expired oxygen $\left(\mathrm{O}_{2}\right)$ and carbon dioxide $\left(\mathrm{CO}_{2}\right)$ were measured using paramagnetic $\mathrm{O}_{2}$ and infrared $\mathrm{CO}_{2}$ analyzers connected to a computerized system (MAX-1, PHYSIO-DYNE Instrument Corp., Quogue, NY) and calibrated against known medical grade gases. The highest $\mathrm{VO}_{2}$ value attained during the graded exercise test was considered $\mathrm{VO}_{2} \max (30)$.

\section{Experimental Protocol}

Subjects meeting inclusion criteria were randomized to the aerobic- or strength-training program. Both programs were 12 weeks in length. Before training, all subjects met individually with a trainer to review their exercise regimens. After that, they exercised on their own, 3-4 times per week, in designated facilities. They were permitted to construct individualized exercise programs so long as they met the criteria below. Adherence to training programs was documented by weekly logs and computerized attendance records. Subjects were contacted on a weekly basis to monitor progress. During these weekly 
contacts, subjects received additional supervision as needed and motivational support to adhere to their regimen

After completion of training, subjects returned for post-training $\mathrm{VO}_{2}$ max and laboratory testing, then began four weeks of sedentary deconditioning during which they were to abstain completely from any form of exercise. After deconditioning, they returned for a final testing session. Data collection staff were blind to training group assignment.

\section{Conditioning Programs}

Aerobic Conditioning-Subjects chose from a series of activities, e.g., cycling on a stationary ergometer, running on a treadmill, or climbing on a Stairmaster. Subjects were instructed to exercise at $70 \%$ of their maximum heart rate (220-age for men, 226-age for women). They were given an initial goal of at least 20 mins aerobic exercise per session and increased duration gradually over two to three weeks, up to 45-60 min. A trainer helped subjects choose a starting workload setting for each machine, and they were instructed to increase the workload over time when they felt able, while maintaining their $70 \%$ of max HR throughout the session. Subjects measured their heart rates manually by palpation.

Strength Training-At the initial session, subjects established a level of effort that permitted them to complete three sets of 10 repetitions for each of the following exercises: bench presses, shoulder presses, quadriceps extensions, biceps curl, lateral pulls, triceps presses, and hamstring curls exercise. Subjects were instructed to increase the weight loads for these exercises by five pounds every two weeks.

\section{Psychophysiology Testing Sessions}

Subjects were tested in the Behavioral Medicine Laboratory after eating a light breakfast and abstaining from caffeinated beverages. ECG electrodes were placed on the right shoulder, on the left anterior axillary line at the 10th intercostal space and in the right lower quadrant. Stretch bands were placed around the subject's chest and abdomen for measurement of respiration (see below). A Finapres blood pressure cuff was placed on the middle finger of the non-dominant hand. Blood pressure data will be reported separately. Subjects were tested three times: before training (baseline), after training (post-training), and after deconditioning (post-deconditioning).

After instrumentation, the subject rested quietly in a comfortable chair during a $10 \mathrm{~min}$ baseline period followed by a 5-min public speaking stressor and a 5-min recovery period. Then the subject was placed in the supine position on a Midland electric tilt table modified to suspend a computer monitor in the subject's visual field for display of the psychological tasks. A numeric keypad, for responding to the arithmetic and Stroop tasks, was secured in a comfortable position relative to the dominant hand. Subjects could not see the keypad but could identify the keys by feel. The subject then rested quietly for $6 \mathrm{~min}$ of adaptation to position, followed by a two minute period for calibration of monitoring devices, and a second 10 min quiet, resting baseline. Subjects then performed the mental arithmetic stressor and the Stroop color-word task, each $5 \mathrm{~min}$ in length and each followed by a $5 \mathrm{~min}$ recovery period. Subjects were instructed to remain silent throughout the procedures. After the second recovery period, the tilt table was moved to the $70^{\circ}$ head-up position and the monitoring devices were recalibrated. Physiological signals were collected for $10 \mathrm{~min}$ in the upright position.

\section{Psychological Stressors}

Public Speaking Task: Subjects were allowed to select one of five controversial topics, e.g., AIDS, welfare, and were informed that their performance would be video-recorded for 
evaluation. After the instruction period, they were permitted to prepare for the speech for five minutes, and then had five minutes to deliver it. A five-minute recovery period followed the speech.

Mental Arithmetic: In this task, subjects were presented with a four digit number on the computer monitor and were instructed to subtract serially by 7's starting with this number, which disappeared after the first answer was entered. At one min intervals, subjects received verbal prompts, e.g., "please subtract faster." This task was not paced by the computer but subjects were instructed to subtract as quickly and accurately as possible.

Stroop Color-Word Task: In this version of the Stroop task, the computer monitor presented color name words (blue, green, yellow, red) in a color which was either congruent or incongruent with the name. The task was to press a key on the keypad corresponding to the color of the letters, not the color name. The task was paced by the computer and an incorrect response or failure to respond rapidly enough resulted in a message indicating "incorrect" on the screen; pacing was automatically adjusted to enable subjects to achieve a $67 \%$ correct response rate

\section{Measurement of Cardiac Autonomic Modulation}

Analog ECG signals were digitized at $500 \mathrm{~Hz}$ by a National Instruments 16 bit A/D conversion board and passed to a microcomputer. The ECG waveform was submitted to an $\mathrm{R}$-wave detection routine implemented by custom-written software, resulting in an RR interval series. Errors in marking of R-waves were corrected by visual inspection. Ectopic beats were corrected by interpolation.

RR Interval Variability-Mean HR and the standard deviation of the RR interval (SDRR), the root mean squared successive difference (rMSSD), and spectral power in the low $(0.04-0.15 \mathrm{~Hz}(\mathrm{LF}))$ and high $(0.15-0.50 \mathrm{~Hz}(\mathrm{HF}))$ frequency bands were computed. Spectra were calculated on 300 second epochs using an interval method for computing Fourier transforms similar to that described by DeBoer, Karamaker, and Strackee (31). Additionally, data were analyzed in $60 \mathrm{sec}$ epochs to allow for analysis of recovery from challenge using the area under the curve method (see below). Prior to computing Fourier transforms, the mean of the RR interval series was subtracted from each value in the series and the series then was filtered using a Hanning window (32) and the power, i.e., variance (in $\mathrm{msec}^{2}$ ), over the LF and HF bands was summed. Estimates of spectral power were adjusted to account for attenuation produced by this filter (32).

\section{Measurement of Blood Pressure}

Blood pressure was measured on a beat-to-beat basis by an Ohmeda Finapres 2300 monitor. Except for the last minute of each period of data acquisition, the servo self-adjust mechanism was disabled. The analog pressure waveform was digitized at $500 \mathrm{~Hz}$ and collected by the microcomputer. A series of systolic and diastolic values were produced by another peak detection program. Errors in marking systole and diastole were corrected interactively using this program. Files of SBP and DBP then were created.

\section{Measurement of Respiration}

Thoracic and abdominal respiration signals were collected by a Respitrace monitor. Signals were submitted to a specially written respiration-scoring program that produced min by min means of respiratory rate. 


\section{Computation of Reactivity and Recovery}

For each variable, reactivity to each task was computed as the difference between the mean value during the task and the mean of the preceding baseline. For each baseline, the two 300 sec epochs were averaged to yield a single value. To increase response stability, data from the arithmetic and Stroop tasks were averaged, as were the recovery periods that followed them (33). The speech task was treated separately because it was delivered in the seated, not the supine, position. To allow for complete equilibration to the upright position, data from the first 5 min epoch after tilt were excluded from analysis. No recovery data were collected after tilt.

We also computed recovery as area under the curve (AUC), constructed from $60 \mathrm{sec}$ epoch length data described previously (34). A greater AUC indicates more complete recovery. For recovery from the arithmetic and Stroop tasks, data were averaged on a minute-by-minute basis (e.g., (Stroop recovery min1 + Math recovery min1)/2) and the recovery curves were constructed from these 1 min averages.

\section{Statistical Analysis}

Data were analyzed in 300-sec epochs for the seated and supine baseline and for the speech, arithmetic, and Stroop task stressors. Recovery periods were analyzed in $60 \mathrm{sec}$ epochs to allow for computation of area under the curve. All indices of RRV were log transformed prior to statistical analysis.

The data were analyzed by performing a 3-way ANOVA - Group (aerobic vs. strength) by Session (baseline, post-training, and after deconditioning), and Period within session (baselines, public speaking, arithmetic, and Stroop tasks, tilt, and recovery) - with models estimating pre-specified contrasts that assess within-group, within- session change between periods (i.e., reactivity) for a given outcome measure, group differences in reactivity within each session, and differential (between groups) change in reactivity across pairs of sessions. A similar modeling procedure was used to assess change in recovery. The study's primary hypothesis - that after training, cardiovascular reactivity would be smaller and recovery would be more rapid in the aerobic training group compared to the strength-training group was addressed by testing the statistical significance of the between-group change in reactivity or recovery across time. In accord with intention-to-treat principles, multi-level mixed modeling software (SAS 9.2 Proc Mixed) was used to generate full-information maximum likelihood (FIML) estimates, using all available data, of the 3-way ANOVA model. Separate analyses were performed for the five outcome measures.

Separate contrasts were specified for the speech task, the combined arithmetic and Stroop task, and tilt test. Comparisons regarding recovery from challenge were also treated separately (for speech task and for combined math/Stroop tasks). Finally, two additional specific contrasts were modeled separately, comparing the three-way interaction across reactivity change scores ( 3 comparisons) and another across recovery change scores ( 2 comparisons), thus providing a discriminating F-test with fewer $\mathrm{df}$ required than the full model.

\section{RESULTS \\ Descriptive Data}

One hundred forty nine healthy men $(\mathrm{N}=58)$ and women $(\mathrm{N}=91)$ were randomized and tested prior to training. Two groups were well balanced with respect to demographic and physical characteristics (Table 1). 101 participants completed training, yielding a dropout rate of $32 \% .87$ participants completed deconditioning. The dropout rates were the same for 
both groups. Dropouts were significantly younger (28.42 vs. 32.17 years, $p=0.003$ ) and there were significantly more women dropouts ( 42 vs. $17, \mathrm{p}=0.037$ ). However, they do not differ in other demographic and physical characteristics.

\section{Effect of Training on Aerobic Capacity}

As we have previously reported, there were significant effects of group assignment $(\mathrm{F}(1,503)=3.83, p=0.0509)$, testing session $(\mathrm{F}(2,503)=68.95, p<.0001)$, gender $(\mathrm{F}(1,503)=46.16, p<.0001), \mathrm{BMI}(\mathrm{F}(1,503)=15.20, p=.0001)$, and age $(\mathrm{F}(1,503)=8.84$, $p=.0031)$ on aerobic capacity. Aerobic capacity increased after training and decreased after deconditioning only in the aerobic group (35).

\section{Impact of Training on Heart Rate Reactivity to and Recovery from Challenge}

Figure 1 presents the HR data for the aerobic (top panel) and strength training (bottom panel) groups throughout the protocol. As this figure indicates, the tasks behaved as expected, producing substantial increases in HR, which recovered after the task ended, consistent with the highly significant effect of period in Table 1 . The figure also suggests that as expected, aerobic but not strength training led to a reduction in HR from baseline to post-training and a return of $\mathrm{HR}$ at post-deconditioning, although this effect achieved only marginal significance.

The group $\mathrm{X}$ session $\mathrm{X}$ period interaction, the test of the primary hypothesis that aerobic training would lead to reduced HR reactivity and more rapid HR recovery, achieved marginal significance, as indicated in Table 2. Examination of the pre-specified contrasts revealed that this effect was produced by marginally significant baseline - post-training difference between reactivity to math/Stroop challenge: after training, HR reactivity to these tasks fell by $0.20 \mathrm{bpm}$ in the aerobic group (5.61 to $5.41 \mathrm{bpm}$ ) compared to a reduction in reactivity of $1.61 \mathrm{bpm}(7.65$ to $6.04 \mathrm{bpm})$ in the strength training group $(\mathrm{t}(122)=1.80 \mathrm{p}=$ $0.07)$. In addition, there was a marginally significant group difference in reactivity to the math/Stroop task from post-training to post-deconditioning. In the aerobic group, reactivity fell from $5.41 \mathrm{bpm}$ at post-training to $3.88 \mathrm{bpm}$ at post-deconditioning. In the strength training group, reactivity fell from $6.04 \mathrm{bpm}$ at time 2 to 5.89 at post-deconditioning $(\mathrm{t}(94.4)$ $=-1.73, p=0.09$ ).

Reactivity to speech and to tilt did not differ between the two training groups in any of the sessions. There was no effect of group assignment on recovery to either speech or the combined math/Stroop tasks. Results did not differ when using the more sensitive AUC approach to quantifying recovery.

\section{Impact of Training on RR Interval Reactivity to and Recovery from Challenge}

Table 2 presents the results of analyses for the four indices of RRV. The highly significant effect of period indicates that RRV fell in response to challenge and then rose during recovery, as Figure 2 shows. For all indices except rMSSD, the group X session interaction achieved marginal significance suggesting, as Figure 2 indicates, that RRV increased from baseline to post-training in the aerobic group, but not in the strength training group and that this effect was reversed in post-deconditioning. In all cases, the group $\mathrm{X}$ session $\mathrm{X}$ period interaction failed to achieve significance, indicating that there was no differential effect of training on reactivity to or recovery from any of the stressors. Operationalizing recovery as AUC did not change the results. Examination of Figure 2, which presents the data for HFRRV for the aerobic (top panel) and strength (bottom panel) training groups, shows how similar the two groups were in response to challenge across the three sessions. 


\section{Impact of Training on BP Reactivity to and Recovery from Challenge}

Table 2 also presents the results of analyses for systolic and diastolic blood pressure. For BP, like HR and RRV, there was a highly significant effect of period, indicating, as Figure 3 shows, that both SBP and DBP rose in response to challenge and fell during recovery. The group $\mathrm{X}$ session interaction failed to achieve significance for both SBP and DBP, indicating that across both groups, there was no BP change from baseline to post-training to postdeconditioning. The group $\mathrm{X}$ session $\mathrm{X}$ period interaction was not significant for SBP or DBP, indicating, as for other outcome variables, that there was no differential effect of training on reactivity or recovery from any of the stressors.

\section{DISCUSSION}

Numerous studies have demonstrated that physical activity is associated with cardioprotection and reduction in all-cause mortality (1-3), so much so that consensus panels consistently recommend exercise as an activity central to good health $(8-10,36)$. Among the many mechanisms proposed to account for the health benefits of exercise is attenuated reactivity to and enhanced recovery from challenge. We conducted a randomized controlled trial to test the hypothesis that aerobic exercise, in contrast to strength training, would lead to attenuated HR and RRV reactivity to and enhanced recovery from cognitive and orthostatic challenge and that sedentary deconditioning would reverse these effects.

As expected, participants randomized to the aerobic but not the strength training condition showed improvements in fitness, measured as aerobic capacity. Moreover, four weeks of sedentary deconditioning reversed these improvements. Correspondingly, there was an across-the-board reduction in HR after 12 weeks of aerobic but not strength training, an effect that was reversed by deconditioning. Nevertheless, improvements in fitness were not associated with reductions in HR reactivity to the public speaking task, the aggregated Stroop and math tasks, or the tilt test. Improvements in fitness had no impact on HR recovery from challenge. Similarly, aerobic training did not alter RR interval variability or $\mathrm{BP}$ reactivity to or recovery from challenge.

These findings contradict many in the field and differences in study design, number and selection of participants, and outcome measure are most likely responsible. Many studies reporting reduced reactivity or improved recovery from challenge are cross-sectional in nature. In their meta-analysis, Forcier et al. reported that fit individuals had reduced HR reactivity to and improved HR recovery from psychological challenge but of the 33 studies they included, 19 were cross-sectional. Of the 14 training studies, only 7 showed an effect on HR reactivity and the total number of healthy participants in these studies was 90 (28). More recently, Rimmele et al. reported reduced autonomic nervous system reactivity to psychological stress in trained participants. However, this finding is based on comparisons of elite and amateur sportsmen and untrained men (37). In a previous study, this group reported similar findings (38). Hamer et al. also reported that greater physical fitness was associated with attenuated autonomic reactivity to stress but in this study as well, these findings were based on cross-sectional comparisons of fitness and reactivity to stress (39).

In addition to design, our study differs from other studies in the outcome measures selected: only HR, RRV, and BP. As Jackson and Dishman demonstrated, in a meta-analysis reviewing 73 studies, the relationship between fitness and reactivity and recovery has been examined on a wide range of dependent variables including but not limited to heart rate, blood pressure, plasma catecholamines, vascular resistance, stroke volume, skin conductance, and muscle sympathetic nerve activity (29). They reported that fitness was associated with slightly greater reactivity to but better recovery from psychological challenge. The effects, however, were smallest in the better-controlled studies and of the 73 
studies they reviewed, only 19 were RCTs. In these 19 studies, there was no improvement in reactivity after training. Thus, our finding of no effect of exercise training on HR or RRV reactivity or recovery is broadly consistent with those employing the most rigorous research designs.

Our findings also provide no support for the cross-stressor adaptation theory. Originally formulated by Sothmann et al. (26), the theory holds that the cardiovascular responses to an acute bout of exercise, e.g., increasing HR, decreasing vagal cardiac control, are attenuated by exercise training and that this cardiovascular adaptation to exercise stress generalizes to responses to other challenges. Mueller et al. suggest that this putative effect is attributable to training-induced diminished sympathetic nervous system responsiveness (40) and support of this view, cite a report by O'Sullivan and Bell (41). This report describes a cross-sectional study in which the HR and BP responses to handgrip, mental arithmetic, and cold pressor were smaller in 8 fit participants compared to 8 unfit ones. Then the unfit participants completed 5 weeks of moderate intensity training and were retested. After training, their responses to the challenges were reduced, a finding that demonstrated reduced sympathetic responsiveness to challenges other than exercise.

Our data, based on a much larger sample, contradict these findings. Moreover, a very recent study specifically addressed the hypothesis that training-induced diminished SNS responsiveness to exercise challenge generalizes to other stressors. Ray and Carter reported that 14 weeks of exercise training failed to alter muscle sympathetic nerve activity responses to mental arithmetic (42). Thus, our data support those of Ray et al. and are inconsistent with the cross-stressor adaptation theory.

Finally, we considered the possibility that the failure to support the hypothesis that aerobic training attenuates reactivity to and improves recovery from psychological challenge was due to insufficient statistical power. Given the sample size of 100 after dropout, we calculated that the study had $80 \%$ power to detect an effect size of 0.44 , equivalent to a reactivity difference of $2 \mathrm{bpm}$ between two groups, at the .05 significance level. Thus, we conclude that the failure to support the hypothesis was not due to insufficient statistical power.

\section{Limitations}

While our findings cast doubt on the attenuation of reactivity to psychological or orthostatic challenge as a mechanism by which increased physical fitness risk of cardiovascular disease, they are limited in important respects. First, they pertain solely to specific measures of cardiovascular function. Improvements in fitness may attenuate reactivity to or enhance recovery from challenge in other cardiovascular measures or other physiological systems such as HPA indices or inflammatory markers. Each of these has been shown to be sensitive to psychological challenge and each is linked to cardiovascular disease outcomes.

Second, our exercise-training program was only moderate in intensity, yielding improvements in aerobic capacity of approximately $15 \%$. It is conceivable that more intensive training programs would produce the expected effects on reactivity and recovery. However, even moderate improvements in exercise capacity are associat ed with cardioprotective effects $(9,10)$. Therefore, it seems unlikely that the failure to support the hypothesis was due to an insufficiently intensive training program.

Third, our participants may not have adhered to the training protocols as intended. Participants were supervised during their initial training session but after that, they exercised on their own and our data on adherence is based solely on self-report. Nevertheless, the aerobic and strength training groups differed precisely as expected on changes in aerobic 
capacity after training and again after deconditioning. Therefore, it appeared that subjects exercised as planned.

\section{Conclusion}

To conclude, we conducted a randomized controlled trial of the impact of aerobic vs. strength training on HR, RRV, and BP reactivity to and recovery from psychological and orthostatic challenge. We found that although the aerobic but not the strength training group showed the expected improvement in aerobic capacity after training and the expected reversal of this effect after sedentary deconditioning, there was no group difference in reactivity to or recovery from challenge. Aerobic conditioning is associated with reduced risk of CAD but attenuated reactivity to or improved recovery from psychological and orthostatic challenge is not likely to be a mechanism.

\section{References}

1. Lakka TA, Venalainen JM, Rauramaa R. Relation of leisure-time activity and cardiorespiratory fitness to the risk of acute myocardial infarction in men. N Engl J Med. 1994; 330:1549-54. [PubMed: 8177243]

2. Sandvik L, Erikssen J, Thaulow E, Erikssen G, Mundal R, Rodahl K. Physical fitness as a predictor of mortality among healthy, middle-aged Norwegian men. N Engl J Med. 1993; 328:533-7. [PubMed: 8426620]

3. Kushi LH, Fee RM, Folsom AR, Mink PJ, Anderson KE, Sellers TA. Physical activity and mortality in postmenopausal women. JAMA. 1997; 277:1287-92. [PubMed: 9109466]

4. Lissner L, Bengtsson C, Björkelund C, Wedel H. Physical activity levels and changes in relation to longevity: A prospective study of Swedish women. Am J Epidemiol. 1996; 143:54-62. [PubMed: 8533747]

5. Heath GW, Hagberg JM, Ehsani AA, Holloszy JO. A physiological comparison of young and older endurance athletes. Journal of Applied Physiology. 1981; 51:634-40. [PubMed: 7327965]

6. Denis C, Chatard JC, Dormois D, Linossier MT, Geyssant A. Effects of endurance training on capillary supply of human skeletal muscle on two age groups (20 and 60 years). Journal of Applied Physiology. 1986; 81:379-83.

7. DeMaria AN, Neumann A, Lee G, Fowler W, Mason DT. Alterations in ventricular mass and performance induced by endurance training in man evaluated by echocardiography. Circulation. 1978; 57:237-44. [PubMed: 618610]

8. Fletcher GF. How to implement physical activity in primary and secondary prevention A statement for healthcare professionals from the task force on risk reduction, American Heart Association. Circulation. 1997; 96:355-7. [PubMed: 9236457]

9. Pearson TA, Bazzarre TL, Daniels SR, Fair JM, Fortmann SP, Franklin BA, Goldstein LB, Hong Y, Mensah GA, Sallis JF Jr, Smith S Jr, Stone NJ, Taubert KA. American Heart Association Guide for Improving Cardiovascular Health at the Community Level: A Statement for Public Health Practitioners, Healthcare Providers, and Health Policy Makers From the American Heart Association Expert Panel on Population and Prevention Science. Circulation. 2003; 107:645-51. [PubMed: 12566381]

10. Pearson TA, Blair SN, Daniels SR, Eckel RH, Fair JM, Fortmann SP, Franklin BA, Goldstein LB, Greenland P, Grundy SM, Hong Y, Houston Miller N, Lauer RM, Ockene IS, Sacco RL, Sallis JF Jr, Smith SC Jr, Stone NJ, Taubert KA. AHA Guidelines for Primary Prevention of Cardiovascular Disease and Stroke: 2002 Update: Consensus Panel Guide to Comprehensive Risk Reduction for Adult Patients Without Coronary or Other Atherosclerotic Vascular Diseases. Circulation. 2002; 106:388-91. [PubMed: 12119259]

11. Wang, J-s; Jen, CJ.; Chen, H-i. Effects of exercise training and deconditioning on platelet function in men. Arteriosclerosis, Thrombosis and Vascular Biology. 1995; 15:1668-74.

12. Scheuer J, Tipton CM. Cardiovascular adaptations to physical training. Annual Review of Physiology. 1977; 39:221-51. 
13. Saul JP, Arai Y, Berger RD, Lilly LS, Colucci WS, Cohen RJ. Assessment of autonomic regulation in chronic congestive heart failure by heart rate spectral analysis. Am J Cardiol. 1988; 61:1292-9. [PubMed: 3376889]

14. Kleiger RE, Miller JP, Bigger JT, Moss AJ. the Multicenter Post-Infarction Research Group. Decreased heart rate variability and its association with increased mortality after acute myocardial infarction. Am J Cardiol. 1987; 59:256-62. [PubMed: 3812275]

15. Bigger JT, Fleiss JL, Steinman RC, Rolnitzky LM, Kleiger RE, Rottman JN. Frequency domain measures of heart period variability and mortality after myocardial infarction. Circulation. 1992; 85:164-71. [PubMed: 1728446]

16. Tsuji H, Larson MG, Venditti FJ, Manders ES, Evans JC, Feldman CL, Levy D. Impact of reduced heart rate variability on risk for cardiac events: The Framingham Heart Study. Circulation. 1996; 94:2850-5. [PubMed: 8941112]

17. Coats AJS, Adampolous S, Radaelli A, McCance A, Meyer TE, Bernardi L, Solda PL, Davey P, Ormerod O, Forfar C, Conway J, Sleight P. Controlled trial of physical training in chronic heart failure. Circulation. 1992; 85:2119-31. [PubMed: 1591831]

18. Treiber FA, Kamarck T, Schneiderman N, Sheffield D, Kapuku G, Taylor T. Cardiovascular reactivity and development of preclinical and clinical disease states. Psychosomatic Medicine. 2003; 65:46-62. [PubMed: 12554815]

19. Gianaros PJ, Salomon K, Zhou F, Owens JF, Edmundowicz D, Kuller LH, Matthews KA. A greater reduction in high-frequency heart rate variability to a psychological stressor is associated with subclinical coronary and aortic calcification in postmenopausal women. Psychosomatic Medicine. 2005; 67:553-60. [PubMed: 16046367]

20. Jennings JR, Kamarck TW, Everson-Rose SA, Kaplan GA, Manuck SB, Salonen JT. Exaggerated Blood Pressure Responses During Mental Stress Are Prospectively Related to Enhanced Carotid Atherosclerosis in Middle-Aged Finnish Men. Circulation. 2004; 110:2198-203. [PubMed: 15451789]

21. Steptoe A, Marmot M. Impaired cardiovascular recovery following stress predicts 3-year increases in blood pressure. J Hypertens. 2005; 23:529-36. [PubMed: 15716693]

22. Schwartz AR, Gerin W, Davidson KW, Pickering TG, Brosschot JF, Thayer JF, Christenfeld N, Linden W. Toward a causal model of cardiovascular responses to stress and the development of cardiovascular disease. Psychosomatic Medicine. 2003; 65:22-35. [PubMed: 12554813]

23. McArdle, WD.; Katch, FI.; Katch, VL. Essentials of Exercise Physiology. Lippincott Williams; Wilkins: 2005.

24. Cole CR, Foody JM, Blackstone EH, Lauer MS. Heart rate recovery after submaximal exercise testing as a predictor of mortality in a cardiovascularly healthy cohort. Ann Intern Med. 2000; 132:552-5. [PubMed: 10744592]

25. Cole CR, Blackstone EH, Pashkow FJ, Snader CE, Lauer MS. Heart-rate recovery immediately after exercise as a predictor of mortality. N Engl J Med. 1999; 341:1351-7. [PubMed: 10536127]

26. Sothmann MS, Buckworth J, Claytor RP, Cox RH, White-Welkley JE, Dishman RK. Exercise training and the cross-stressor adaptation hypothesis. Exercise and sport sciences reviews. 1996; 24:267-87. [PubMed: 8744253]

27. Crews DJ, Landers DM. A meta-analytic review of aerobic fitness and reactivity to psychosocial stressors. Med Sci Sports Exerc. 1987; 19:S114-20. [PubMed: 3316910]

28. Forcier K, Stroud LR, Papandonatos GD, Hitsman B, Reiches M, Krishnamoorthy J, Niaura R. Links between physical fitness and cardiovascular reactivity and recovery to psychological stressors: A meta-analysis. Health Psychol. 2006; 25:723-39. [PubMed: 17100501]

29. Jackson EM, Dishman RK. Cardiorespiratory fitness and laboratory stress: a meta-regression analysis. Psychophysiology. 2006; 43:57-72. [PubMed: 16629686]

30. Buchfuhrer MJ, Hansen JE, Robinson TE, Sue DY, Wasserman K, Whipp B. Optimizing the exercise protocol for cardiopulmonary assessment. Journal of Applied Physiology. 1983; 55:155864. [PubMed: 6643191]

31. deBoer RW, Karemaker JM, Strackee J. Comparing spectra of a series of point events, particularly for heart rate variability spectra. IEEE Trans Biomed Eng. 1984; BME-31:384-7. [PubMed: 6745974] 
32. Harris FJ. On the use of windows for harmonic analysis with the discrete Fourier transform. Proceedings of the IEEE. 1978; 66:51-83.

33. Kamarck TW, Jennings JR, Debski TT, Glickman-Weiss E, Johnson PS, Eddy JJ, Manuck SB. Reliable measures of behaviorally-evoked cardiovascular reactivity from a PC-based test battery: Results from student and community samples. Psychophysiology. 1992; 29:17-28. [PubMed: 1609024]

34. Shcheslavskaya OV, Burg MM, McKinley PS, Schwartz JE, Gerin W, Ryff CD, Weinstein M, Seeman TE, Sloan RP. Heart Rate Recovery After Cognitive Challenge Is Preserved With Age. Psychosomatic Medicine. 2010; 72:128-33. [PubMed: 20028831]

35. Sloan RP, Shapiro PA, DeMeersman RE, Bagiella E, Brondolo EN, McKinley PS, Slavov I, Fang Y, Myers MM. The Effect of Aerobic Training and Cardiac Autonomic Regulation in Young Adults. Am J Public Health. 2009; 99:921-8. [PubMed: 19299682]

36. US Department of Health and Human Services. Morbidity and Mortality Weekly Report. Vol. 47. Atlanta GA: Centers for Disease Control and Prevention; 1998. Recommendations for prevention and control of hepatitis $\mathrm{C}(\mathrm{HCV})$ infection and $\mathrm{HCV}$-related chronic disease.

37. Rimmele U, Seiler R, Marti B, Wirtz PH, Ehlert U, Heinrichs M. The level of physical activity affects adrenal and cardiovascular reactivity to psychosocial stress. Psychoneuroendocrinology. 2009; 34:190-8. [PubMed: 18922645]

38. Rimmele U, Zellweger BC, Marti B, Seiler R, Mohiyeddini C, Ehlert U, Heinrichs M. Trained men show lower cortisol, heart rate and psychological responses to psychosocial stress compared with untrained men. Psychoneuroendocrinology. 2007; 32:627-35. [PubMed: 17560731]

39. Hamer M, Steptoe A. Association Between Physical Fitness, Parasympathetic Control, and Proinflammatory Responses to Mental Stress. Psychosomatic Medicine. 2007; 69:660-6. [PubMed: 17724255]

40. Mueller PJ. Exercise Training And Sympathetic Nervous System Activity: Evidence For Physical Activity Dependent Neural Plasticity Clinical and Experimental Pharmacology and Physiology. 2007; 34:377-84.

41. O'Sullivan SE, Bell C. Training reduces autonomic cardiovascular responses to both exercisedependent and -independent stimuli in humans. Auton Neurosci. 2001; 91:76-84. [PubMed: 11515804]

42. Ray CA, Carter JR. Effects of aerobic exercise training on sympathetic and renal responses to mental stress in humans. Am J Physiol Heart Circ Physiol. 2010; 298:H229-34. [PubMed: 19915172]

\section{Abbreviations}

$\begin{array}{ll}\text { RCT } & \text { Randomized Controlled Trial } \\ \text { RRV } & \text { RR Interval Variability } \\ \text { BP } & \text { Blood Pressure } \\ \text { CAD } & \text { Coronary Artery Disease } \\ \text { HR } & \text { Heart Rate } \\ \text { RQ } & \text { Respiratory Quotient } \\ \text { ECG } & \text { Electrocardiogram } \\ \text { SDRR } & \text { Standard Deviation of RR Intervals } \\ \text { LF } & \text { Low Frequency } \\ \text { HF } & \text { High Frequency } \\ \text { AUC } & \text { Area Under the Curve } \\ \text { rMSSD } & \text { Root Mean Squared Successive Difference }\end{array}$




$\begin{array}{ll}\text { BMI } & \text { Body Mass Index } \\ \text { SNS } & \text { Sympathetic Nervous System } \\ \text { ln } & \text { Natural log }\end{array}$




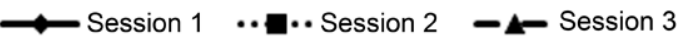
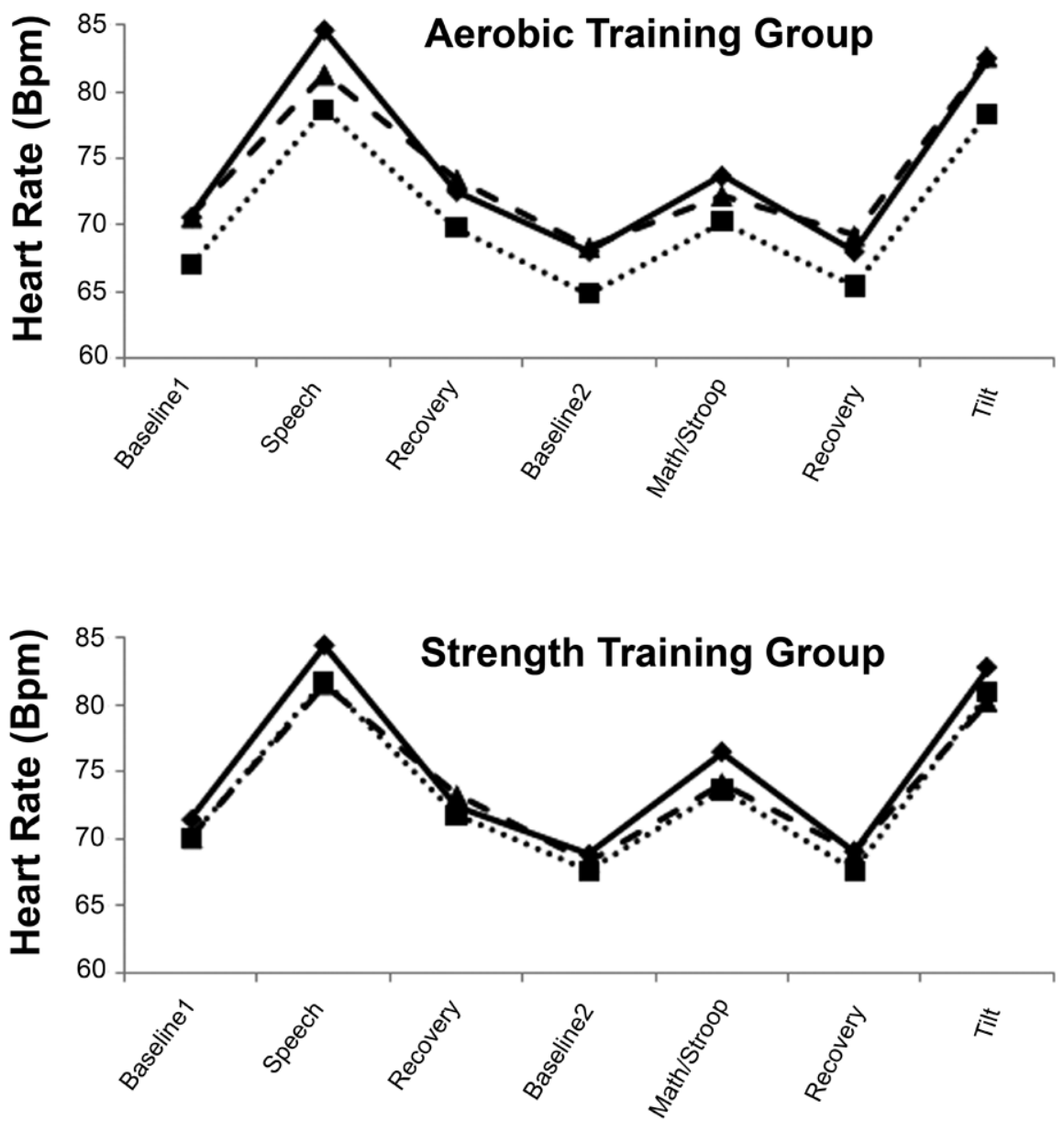

Figure 1.

Heart rate (bpm) at rest and in response to and recovery from cognitive and orthostatic challenge during sessions 1 (solid line), 2 (dotted line), and 3 (broken line) in the aerobic and strength training groups. 

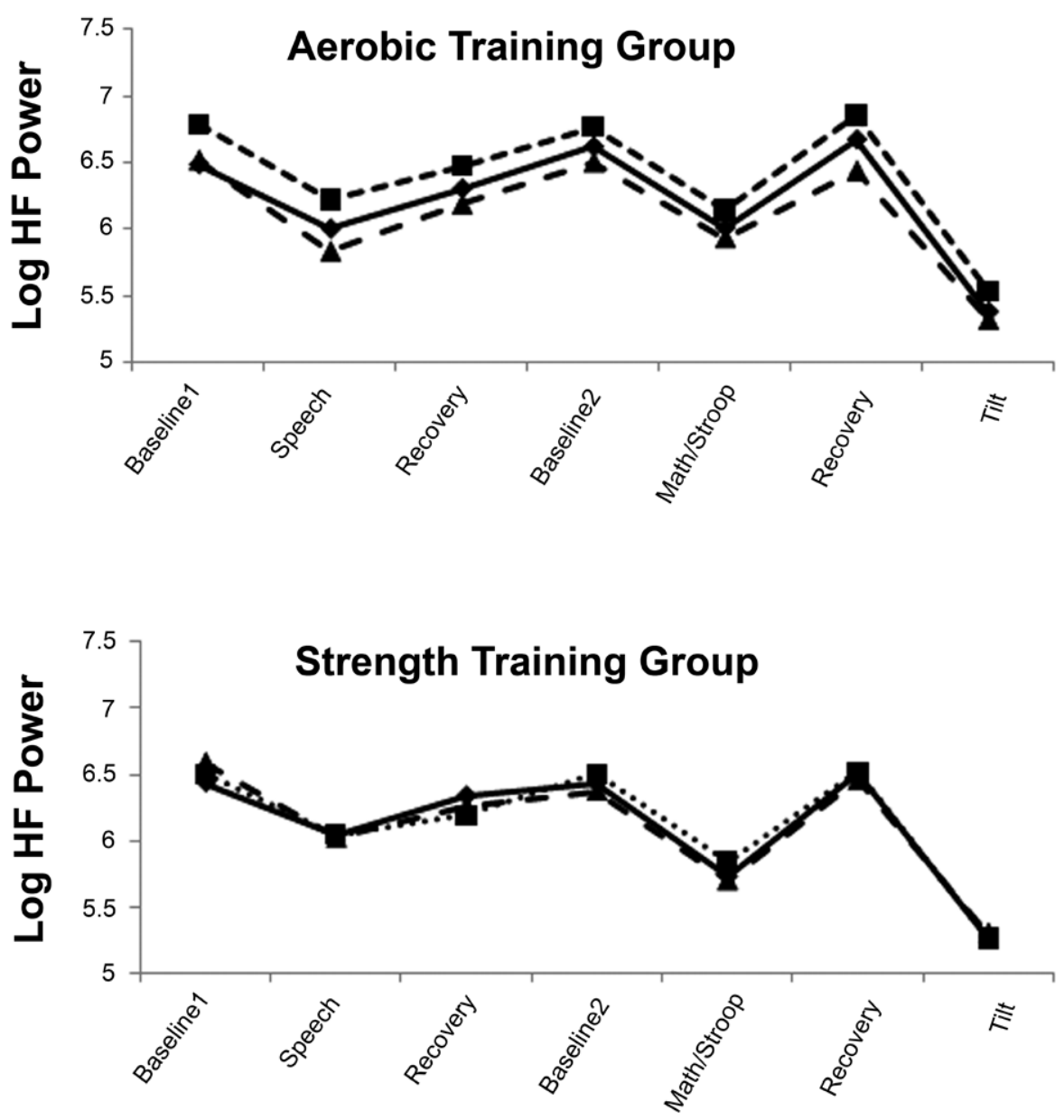

Figure 2.

High frequency RR interval variability (ln $\mathrm{msec}^{2}$ ) at rest and in response to and recovery from cognitive and orthostatic challenge during sessions 1 (solid line), 2 (dotted line), and 3 (broken line) in the aerobic and strength training groups. 
$\longrightarrow$ Session $1 \quad$..e. Session $2 \quad \longrightarrow$ Session 3
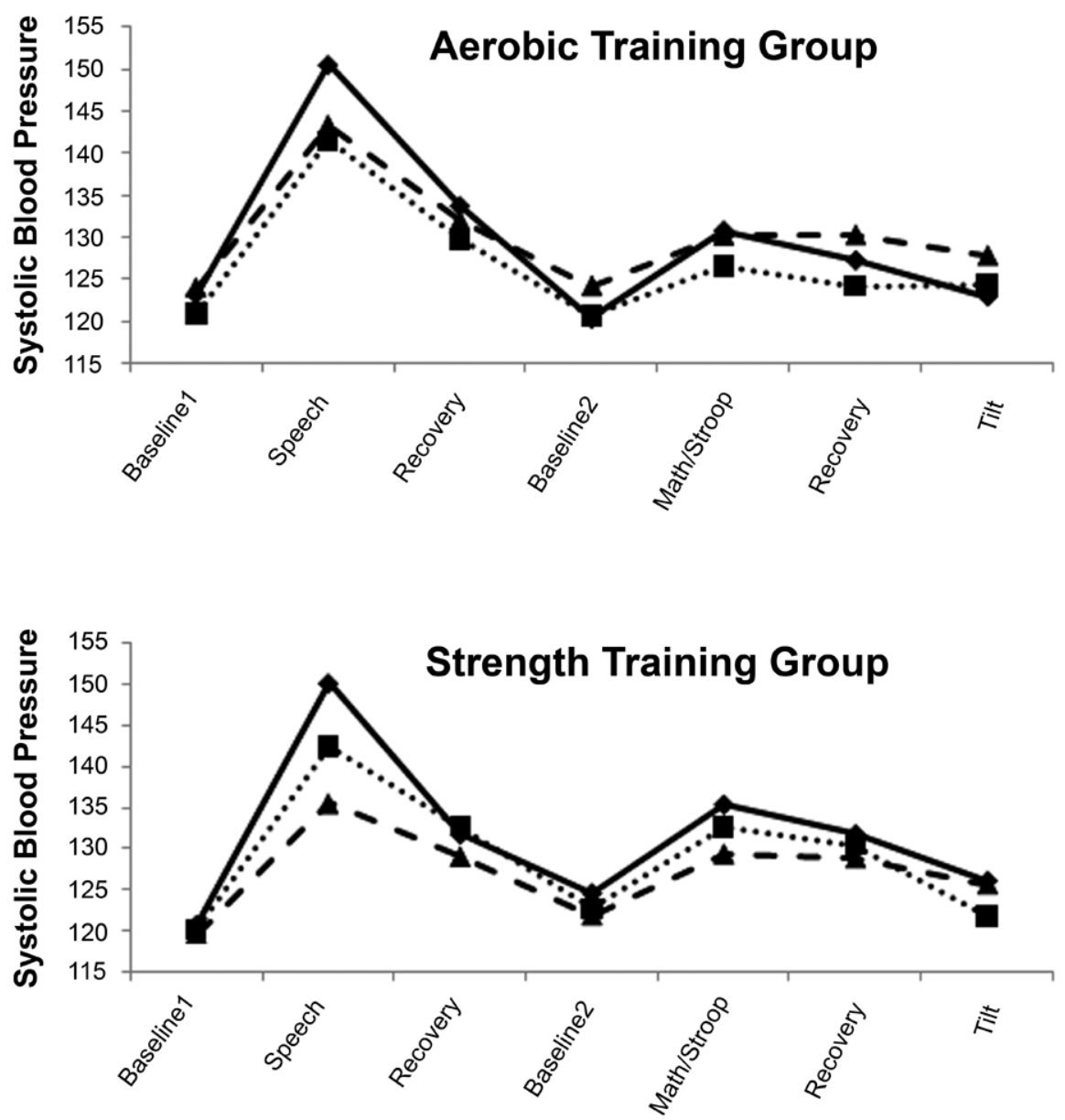

Figure 3.

Systolic blood pressure $(\mathrm{mmHg})$ at rest and in response to and recovery from cognitive and orthostatic challenge during sessions 1 (solid line), 2 (dotted line), and 3 (broken line) in the aerobic and strength training groups. 


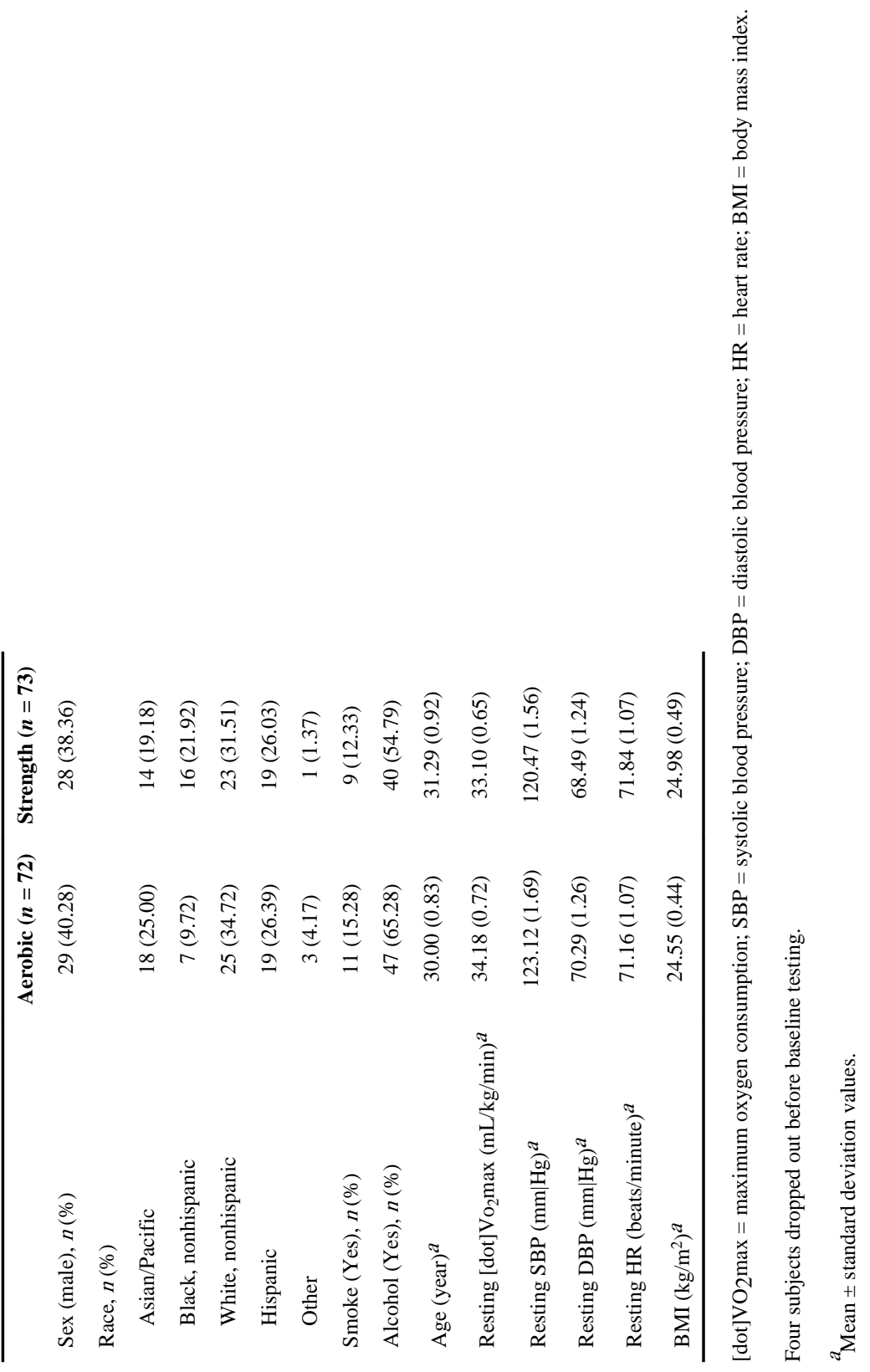

Psychosom Med. Author manuscript; available in PMC 2012 May 13. 


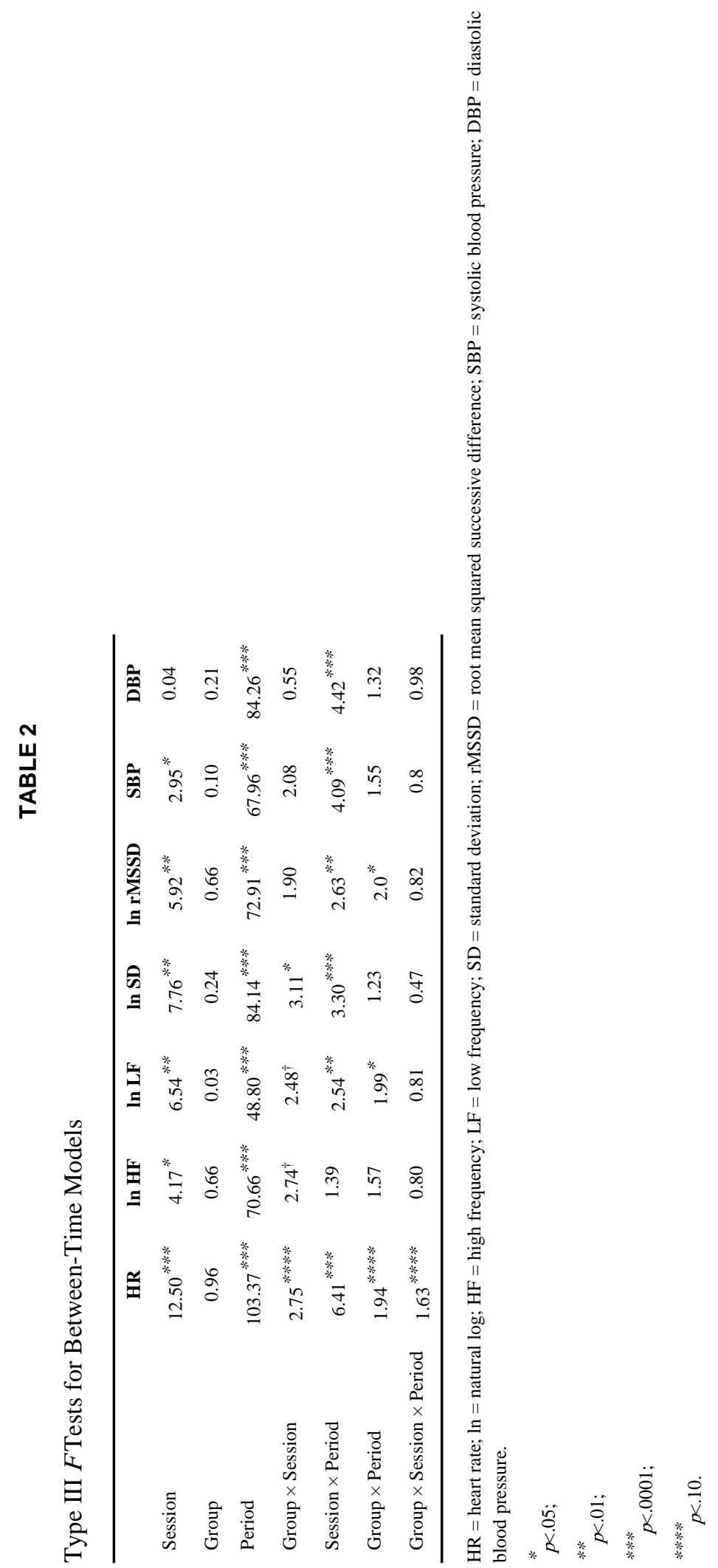

